\title{
FDG PET-CT demonstration of metastatic neuroendocrine tumor of prostate
}

Yiyan Liu

Address: Nuclear Medicine Service, Department of Radiology, University Hospital, UMDNJ, Newark, New Jersey, USA

Email: Yiyan Liu - liuyl@umdnj.edu

Published: 19 June 2008

World Journal of Surgical Oncology 2008, 6:64 doi:10.1 186/1477-78/9-6-64

This article is available from: http://www.wjso.com/content/6/1/64

(c) 2008 Liu; licensee BioMed Central Ltd.

This is an Open Access article distributed under the terms of the Creative Commons Attribution License (http://creativecommons.org/licenses/by/2.0), which permits unrestricted use, distribution, and reproduction in any medium, provided the original work is properly cited.
Received: II October 2007

Accepted: 19 June 2008

\begin{abstract}
Background: FDG PET-CT is generally not suitable for diagnosing prostate cancer because of low glycolysis of the tumor cells. Neuroendocrine differentiation of the prostate cancer is often associated with early visceral metastasis and dismal prognosis, which is resulted from changed metabolic and regulatory pathways.

Case presentation: A case is reported in this paper that FDG PET-CT demonstrates intense uptake of neuroendocrine tumor of the prostate and multiple metastases.

Conclusion: There is high glycolysis and strong FDG-avidity of neuroendocrine tumor of the prostate, which is similar to that of high grade of neuroendocrine tumor in other tissue and organs. In some selected cases of prostate neuroendocrine cancer, whole body FDG PET-CT may be helpful for detection of metastatic disease.
\end{abstract}

\section{Background}

Positron emission tomography (PET) is a new imaging modality which has been widely used for detection of metastasis in various malignancies. The most used radiotracer, F18-fluorodeoxyglucose (FDG) is for evaluation of glycolysis and glucose transporter expression. It is well known that most of malignant tumors display increased glucose metabolism. Unfortunately FDG-PET has not been very helpful in prostate cancer because of low glycolysis of the tumor cells. In addition, physiologic urinary excretion of FDG can interfere with imaging of the pelvis [1-3].

Neuroendocrine differentiation of the prostate cancer contributes to the progression of the disease and often associated with visceral metastases and dismal prognosis $[4,5]$. We herein describe the case of a prostate cancer that had neuroendocrine differentiation and multiple metastatic lesions detected by FDG PET-CT.

\section{Case presentation}

A 79 year old male with a history of prostate cancer was treated with external radiation and hormone a few years ago. He recently developed gross hematuria and renal failure. CT scan showed bladder mass, hydronephrosis and small lung nodules, but no liver lesion or retroperitoneal lymphadenopathy was noted. The patient underwent nephrostomies and prostate biopsy.

Immunohistochemical studies of the prostate tissue revealed positive staining of the tumor cells for chromogranin, synaptophysin and neuro-specific enolase. The samples were negative for cytokeratin and PSA. In view of the patient's history of prostate adenocarcinoma, the findings were consistent with a high grade of neuroendocrine differentiation.

The patient's whole body bone scintigraphy was negative. The medical oncologist recommended, the patient was 
also strongly interested in cystoprostatectomy with ileal conduit followed by chemotherapy. As a final pre-surgical work-up, the patient had FDG PET/CT, which demonstrated tumor invasion and infiltration to the bladder as well as multiple metastastic lesions in the liver, lungs and lymph nodes (Figure 1, 2, 3, 4). Compared to a CT less

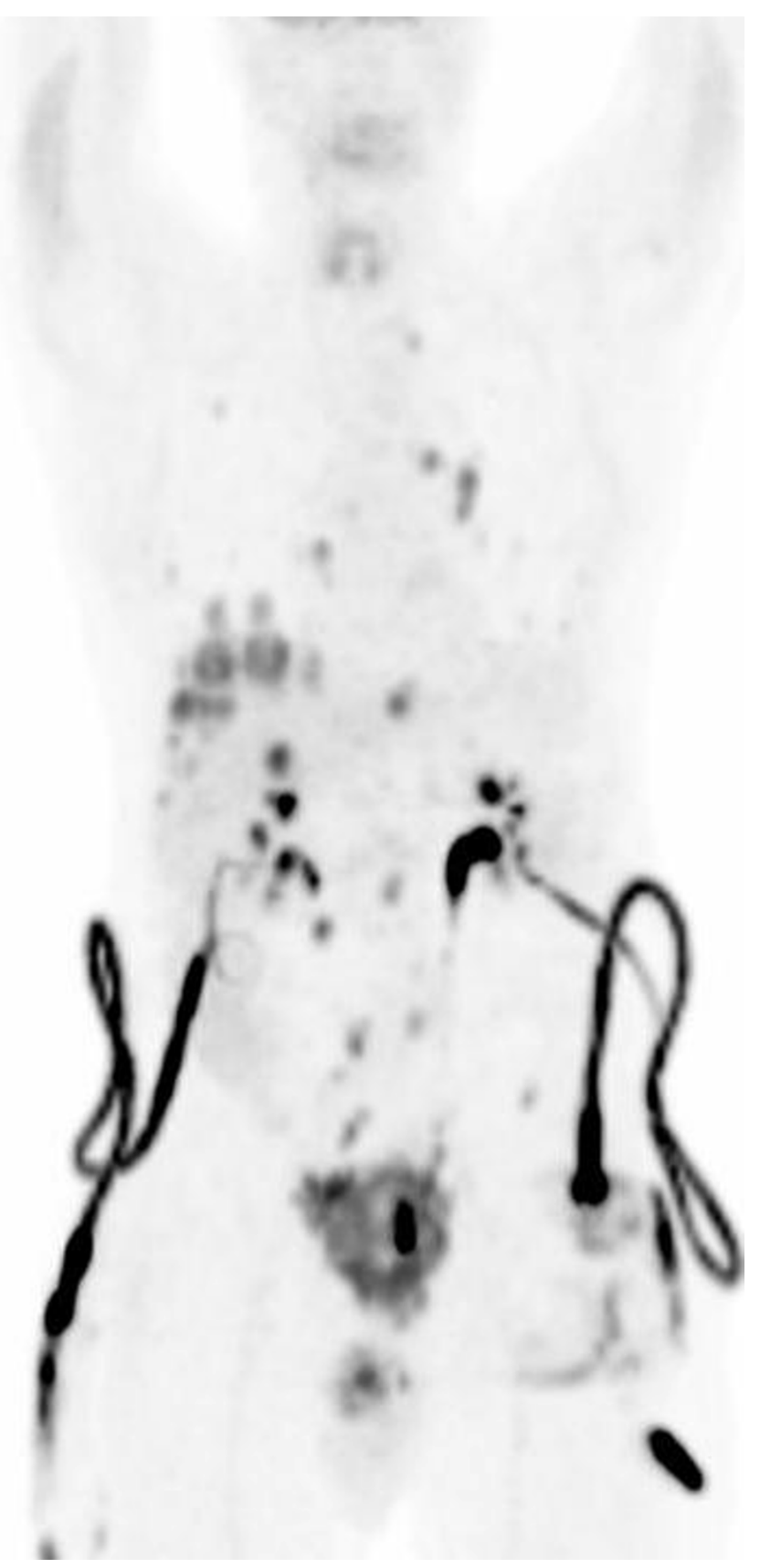

Figure I

Maximum intensity projection (MIP) of the whole body FDG PET-CT imaging. There is intense uptake in the prostate tumor with invasion and infiltration to the bladder wall. Multiple FDG-avid metastatic lesions are noted in the liver, Lungs and lymph nodes of the mediastinum and retroperitoneum. than two months earlier, PET-CT findings suggested marked progression of prostate tumor and multiple new metastases. Therefore, scheduled surgery was cancelled and the patient was treated with chemotherapy (Topotecan) in a hospice facility.

\section{Discussion}

Neuroendocrine tumor of the prostate is featured by early visceral rather than bone metastases [6]. In this case, a CT scan two months earlier was negative in the liver and for lymphadenopathy, but FDG PET-CT demonstrated extensive hepatic lesions as well as nodal and lung metastases while bone scan was still negative.

FDG-PET scan has its advantages of metabolic and molecular imaging, therefore early detection of malignant disease. In addition, routine whole body imaging make it best imaging modality for staging and restaging of most of the malignant diseases. In prostate adenocarcinoma, FDG-PET often does not display increased uptake. Liu et al found only $4 \%$ sensitivity for detecting primary prostate cancer with FDG-PET [7]. But using continuous bladder irrigation, Oyama et al found an increased sensitivity for detecting the prostate tumor [8]. Patients showing increasing prostate specific antigen (PSA) after definite local therapy for prostate cancer represent a diagnostic dilemma. FDG-PET may identify local recurrence and distant metastases with increasing PSA [9]. In addition, Morris et al reported that using PSA levels, bone scintigraphy and soft tissue imaging as references, FDG-PET might be a promising outcome measure after chemotherapy in prostate cancer [10].

With neuroendocrine differentiation, the tumor has different biological behavior [4]. The cells involved in this process secrete a variety of factors that can influence growth patterns and metabolic pathways [11]. This case suggests very high glycolysis and strong FDG-avidity of neuroendocrine tumor of the prostate, which is similar to that of high grade of neuroendocrine tumor in other tissue and organs [12].

To our knowledge, this is the first report of FDG-PET application in neuroendocrine tumor of the prostate and metastatic disease. In some selected cases of neuroendocrine tumor of the prostate, whole body FDG-PET may be helpful for detection of metastasis and therefore change patient's management.

\section{Conclusion}

Neuroendocrine tumor of the prostate demonstrates different metabolic characteristics from adenocarcinoma. It has high FDG avidity and often demonstrates early visceral metastases. In some selected cases, FDG-PET may be 

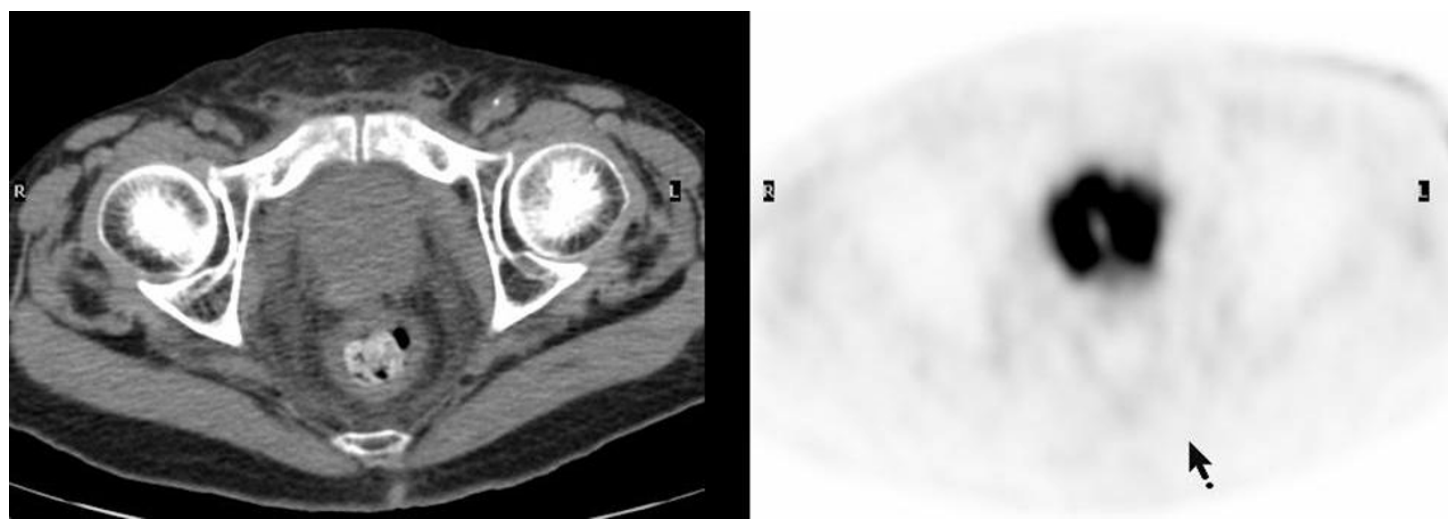

Figure 2

Neuroendocrine differentiation of the prostate cancer displays high grade of FDG uptake on transaxial PET-CT images, which is different from that noted in most of adenocarcinoma of the prostate.

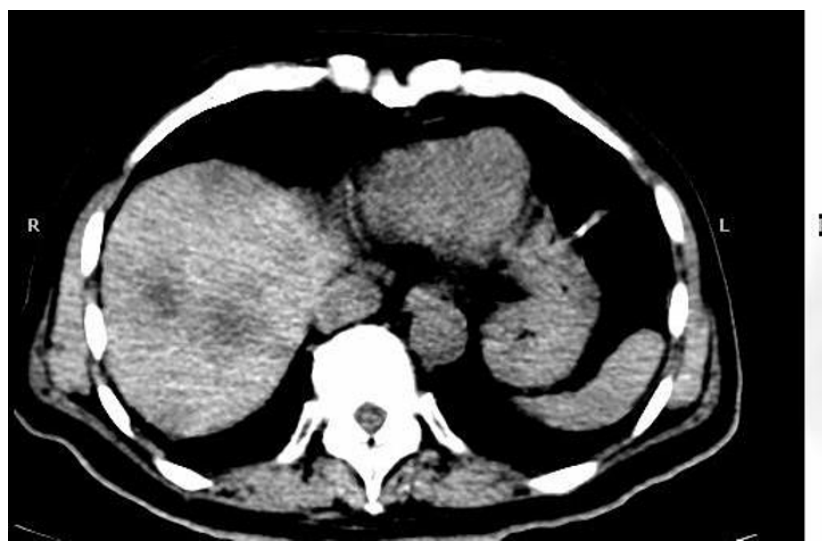

2

Figure 3

FDG PET-CT images demonstrate multiple necrotic hepatic metastases while bone scan and CT two months earlier were negative.

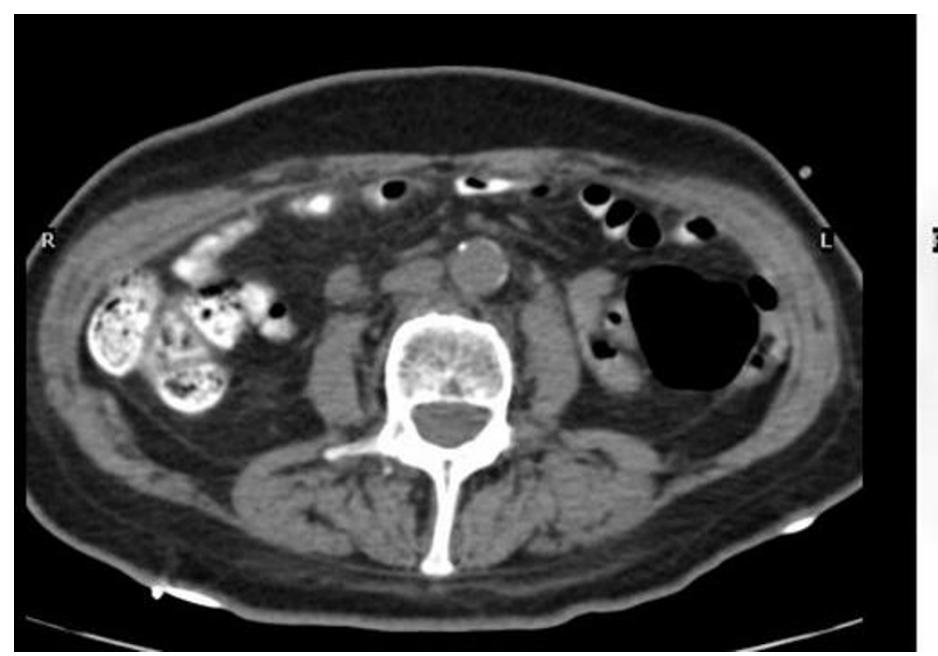

Figure 4

FDG PET-CT images demonstrate a $1.3 \mathrm{~cm}$ aortocaval lymph node with intense uptake consistent with metastatic disease. 
an ideal imaging modality and helpful for identifying metastatic disease.

\section{Competing interests}

The author declares that he has no competing interests.

\section{Authors' contributions}

YL conceived and designed the study, and prepared the draft and final manuscript.

\section{Acknowledgements}

Written consent was obtained from the patient for publication of this case report.

\section{References}

I. Powles T, Murray I, Brock C: Molecular position emission tomography and PET/CT imaging in urological malignancies. Eur Urol 2007, 5 I:I5II-I52|.

2. Effert PJ, Bares R, Handt S: Metabolic imaging of untreated prostate cancer by positron emission tomography with I 8F-FDG. J Urol 1996, I 55:994-998.

3. Hofer C, Laubenbacher C, Block T: FDG-PET is useless for the detection of local recurrence after radical prostatectomy. Eur Urol 1999, 36:31-35.

4. Slovin S: Neuroendocrine differentiation in prostate cancer: a sheep in wolf's clothing? Nat Clin Pract Urol 2006, 3: I38-I44.

5. Huang J, Yao JL, di Sant'Agnese PA: Immunohistochemical characterization of neuroendocrine cells in prostate cancer. Prostate 2006, 66: I399-I406.

6. Pouessel D, Gallet B, Bibeau F: Liver metastases in prostate caicinoma: clinical characteristic and outcome. BJU Int 2007, 99:807-8II.

7. Liu IJ, Zafar MB, Lai YH: Fluorodeoxyglucose positron emission tomography studies in diagnosis and staging of clinically organ-confined prostate cancer. Urology 200I, 57: I08-II5.

8. Oyama N, Akino H, Suzuki Y: FDG PET for evaluating the change of glucose metabolism in prostate cancer after androgen ablation. Nucl Med Commun 200I, 22:963-968.

9. Schoder H, Herrmann K, Gonen M: 2-[I8F]fluoro-2-deoxyglucose positron emission tomography for the detection of disease in patients with prostate-specific antigen relapse after radical prostatectomy. Clin Cancer Res 2005, I I:476I-4769.

10. Morris MJ, Akhurst T, Larson SM: Fluorodeoxyglucose positron emission tomography as an outcome measure for castrate metastatic prostate cancer treated with antimicrotubule chemotherapy. Clin Cancer Res 2005, I I:3210-32 I6.

II. Hansson J, Abrahamsson PA: Neuroendocrine differentiation in prostate carcinoma. Scand J Urol Nephrol 2003, 2 I 2:28-36.

12. Sundin A: PET in the diagnosis of neuroendocrine tumors. Ann NY Acad Sci 2004, I 0 I 4:246-257.
Publish with Biomed Central and every scientist can read your work free of charge

"BioMed Central will be the most significant development for disseminating the results of biomedical research in our lifetime. "

Sir Paul Nurse, Cancer Research UK

Your research papers will be:

- available free of charge to the entire biomedical community

- peer reviewed and published immediately upon acceptance

- cited in PubMed and archived on PubMed Central

- yours - you keep the copyright

Submit your manuscript here:

http://www.biomedcentral.com/info/publishing_adv.asp
BioMedcentral 